\title{
An autoinflammatory neurological disease due to interleukin 6 hypersecretion
}

\author{
Ettore Salsano ${ }^{1 *}$, Ambra Rizzo², Gloria Bedini ${ }^{2,3}$, Loris Bernard4, Valentina Dall'Olio ${ }^{4}$, Sara Volorio ${ }^{4}$, \\ Monica Lazzaroni ${ }^{2}$, Isabella Ceccherini ${ }^{5}$, Dejan Lazarevic ${ }^{6}$, Davide Cittaro ${ }^{6}$, Elia Stupka ${ }^{6}$, Rosina Paterra ${ }^{1}$, \\ Laura Farina ${ }^{7}$, Mario Savoiardo ${ }^{7}$, Davide Pareyson ${ }^{1}$ and Francesca L Sciacca ${ }^{2}$
}

\begin{abstract}
Autoinflammatory diseases are rare illnesses characterized by apparently unprovoked inflammation without hightiter auto-antibodies or antigen-specific T cells. They may cause neurological manifestations, such as meningitis and hearing loss, but they are also characterized by non-neurological manifestations. In this work we studied a 30-year-old man who had a chronic disease characterized by meningitis, progressive hearing loss, persistently raised inflammatory markers and diffuse leukoencephalopathy on brain MRI. He also suffered from chronic recurrent osteomyelitis of the mandible. The hypothesis of an autoinflammatory disease prompted us to test for the presence of mutations in interleukin-1-pathway genes and to investigate the function of this pathway in the mononuclear cells obtained from the patient. Search for mutations in genes associated with interleukin-1-pathway demonstrated a novel NLRP3 (CIAS1) mutation (p.I288M) and a previously described MEFV mutation (p.R761H), but their combination was found to be non-pathogenic. On the other hand, we uncovered a selective interleukin- 6 hypersecretion within the central nervous system as the likely pathogenic mechanism. This is also supported by the response to the anti-interleukin-6-receptor monoclonal antibody tocilizumab, but not to the recombinant interleukin-1-receptor antagonist anakinra. Exome sequencing failed to identify mutations in other genes known to be involved in autoinflammatory diseases. We propose that the disease described in this patient might be a prototype of a novel category of autoinflammatory diseases characterized by prominent neurological involvement.
\end{abstract}

Keywords: Anakinra, Aseptic meningitis, NLRP3 (CIAS1), Hearing loss, Interleukin-1, Interleukin-6, Leukoencephalopathy, MEFV, Tocilizumab

\section{Background}

Autoinflammatory diseases are rare monogenic or multifactorial (complex) illnesses, characterized by apparently unprovoked inflammation without high-titer autoantibodies or antigen-specific $\mathrm{T}$ cells $[1,2]$. Autoinflammatory diseases may cause neurological manifestations, such as meningitis and hearing loss [3,4], but they are also characterized by non-neurological manifestations, such as cutaneous and articular symptoms and signs [1,5]. Among the already recognized autoinflammatory disorders are autosomal dominant diseases related to NLRP3 (CIAS1) mutations, including chronic infantile neurologic cutaneous articular syndrome (CINCA) and

\footnotetext{
* Correspondence: ettore.salsano@istituto-besta.it

${ }^{1}$ UO Neurologia VIII, Department of Clinical Neurosciences, IRCCS

Foundation, "C. Besta" Neurological Institute, Milan 20133, Italy

Full list of author information is available at the end of the article
}

Muckle-Wells syndrome (MWS), and the autosomal recessive (AR) familial Mediterranean fever (FMF) due to $M E F V$ mutations. There are, however, patients with autoinflammatory phenotypes without known genetic mutations [2]. Here, we pinpoint an autoinflammatory disease due to selective IL- 6 hypersecretion and characterized by predominant central nervous system (CNS) involvement.

\section{Case presentation}

In March 2006, a 24-year-old Italian male patient was admitted for chronic headache (more severe in the morning), intermittent, low-grade fever and recurrent episodes of double vision that first occurred in March 2004. He also had a single tonic-clonic seizure in July 2004, for which no anti-epileptic therapy was started. His familial and past histories were unremarkable, 
except for chronic recurrent osteomyelitis of the mandible manifesting with repetitive mandibular pain and swelling, since the age of 20. Neurological examination revealed bilateral papilledema and increased deep tendon reflexes. No extra-neurological signs were present. Laboratory investigations revealed raised inflammatory markers and mild anemia. Brain magnetic resonance imaging (MRI) showed diffuse T2-weighted hyperintensity in the white matter, patchy involvement of the basal ganglia and thalami, and arachnoid cysts. Brain computed tomography (CT) showed tiny subcortical calcifications (Figure 1 and Additional file 1). Lumbar puncture revealed increased opening pressure $\left(40 \mathrm{cmH}_{2} \mathrm{O}\right)$, raised proteins and mild pleocytosis (see Table 1 for details). Despite extensive investigations (see Additional file 1), no infection was found and no autoimmune marker was demonstrated, except for fluctuating (negative to 1:640) titers of antinuclear antibodies (ANAs). Steroid therapy, started in October 2006, caused rapid clinical improvement with disappearance of headache, fever, papilledema, double vision, and mandibular osteomyelitis. However, headache reappeared when prednisone was tapered down to $30 \mathrm{mg} /$ day, despite the co-administration of azathioprine $200 \mathrm{mg} /$ day, and the patient developed progressive hearing loss, postural tremor and cushingoid features. Laboratory investigations still showed raised inflammatory markers, mild anemia, elevated cerebrospinal fluid (CSF) white-cell count (with a variable number of polymorphonuclear leukocytes), and proteinuria $(1 \mathrm{~g} / 24 \mathrm{~h})$. Renal biopsy revealed only fusion of podocyte processes.

Chronic autoinflammatory disease was hypothesized, despite the lack of extra-neurological manifestations except for mandibular osteomyelitis.

\section{Methods}

\section{DNA Sampling and genetic analyses}

Genomic DNA for gene sequencing was isolated from peripheral blood mononuclear cells (PBMCs) using standard methods, and then stored at $+4^{\circ} \mathrm{C}$. Mutations in NLRP3 (exon 3) [NM_001243133, RefSeq], IL6 [NM_000600, RefSeq], LIN28A [NM_024674, RefSeq], MEFV (exons 1to 10) [NM_000243, RefSeq], MIRLET7A3 [NR_029478, RefSeq], $M V K$ (exons 2, and 8 to 11) [NM_000431, RefSeq], and TNFRSF1A (exons 2-4) [NM_001065, RefSeq] were searched for by direct sequencing. In particular, to search for mutations in the IL6 gene, all six exons, including the $5^{\prime}$-UTR

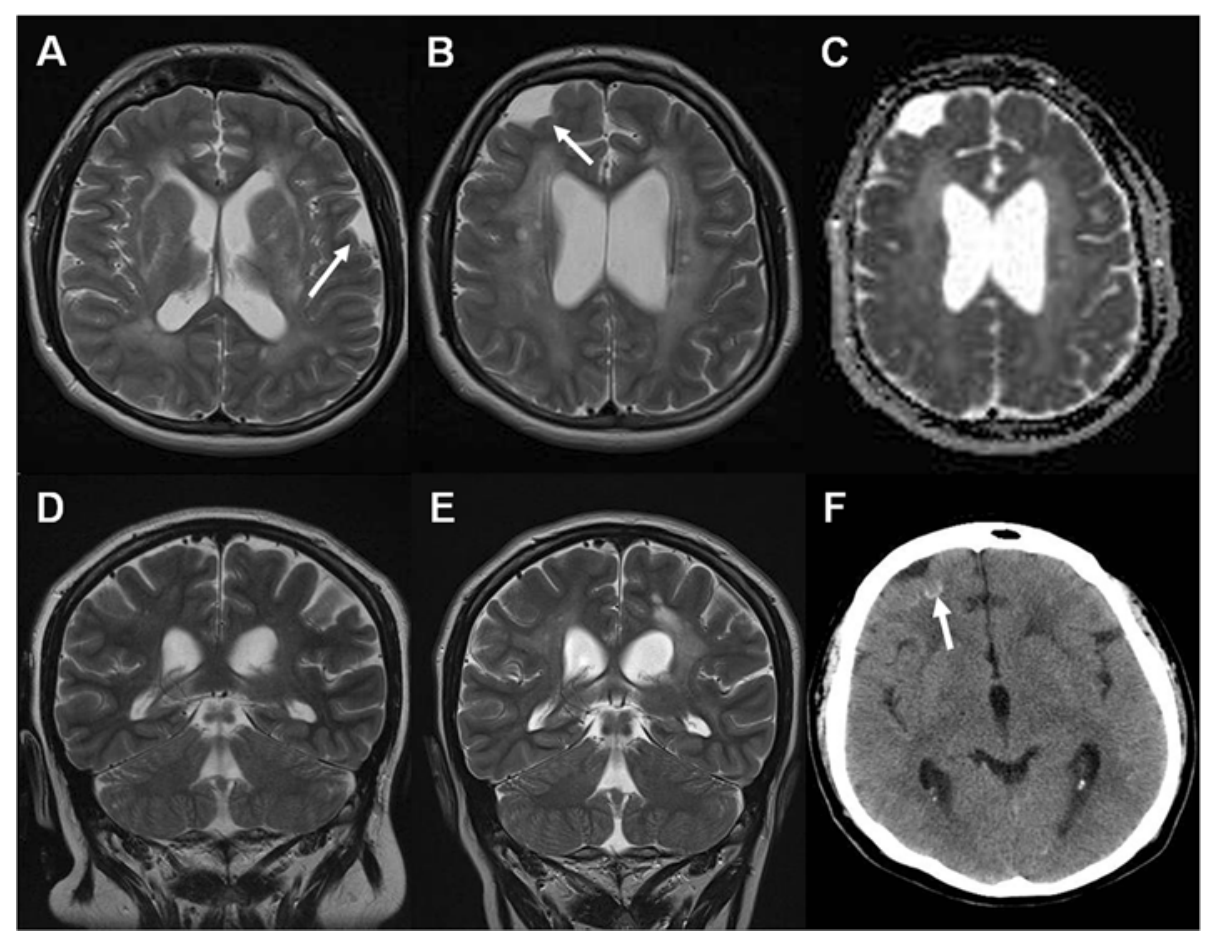

Figure 1 Neuroradiological findings in different examinations. Last magnetic resonance imaging (MRI) study (A and $\mathbf{B}$, axial T2-weighted images; $\mathbf{C}$, apparent diffusion coefficient (ADC) map) shows diffuse hyperintensities in the white matter, patchy involvement of the basal ganglia and thalami, and arachnoid cysts (arrows). ADC is increased, consistent with increased water content in the brain tissue. Comparison of MRI studies obtained 4 years apart (D, E, coronal T2-weighted images) shows progression of the leukoencephalopathy, decrease in size of the subarachnoid spaces along the convexity, and slight enlargement of the ventricles. Recent computed tomography (CT) scan (F) demonstrates tiny subcortical calcifications (arrows). See Additional file 1 for further details. 
Table 1 Key clinical features of our patient from 2004 to 2011

\begin{tabular}{|c|c|c|c|c|c|c|c|c|c|c|}
\hline & April $2004^{1}$ & March 2006 & September 2006 & October 2006 & $\begin{array}{l}\text { September } \\
2007\end{array}$ & July 2008 & $\begin{array}{l}\text { November } \\
2008\end{array}$ & October 2009 & $\begin{array}{l}\text { September } \\
2011\end{array}$ & $\begin{array}{l}\text { September } \\
2011\end{array}$ \\
\hline Clinical manifestations & $\begin{array}{l}\text { Transient double } \\
\text { vision }\end{array}$ & $\begin{array}{l}\text { Intermittent fever, } \\
\text { chronic headache } \\
\text { (> morning), recurrent } \\
\text { episodes of double } \\
\text { vision, papilledema, } \\
\text { one tonic-clonic seizure }\end{array}$ & $\begin{array}{l}\text { Intermittent fever, } \\
\text { chronic headache } \\
\text { (> morning), recurrent } \\
\text { episodes of double } \\
\text { vision, papilledema }\end{array}$ & No symptom & No symptom & $\begin{array}{l}\text { Morning } \\
\text { headache, } \\
\text { one episode } \\
\text { of vomiting }\end{array}$ & $\begin{array}{l}\text { Morning } \\
\text { headache, } \\
\text { hearing loss, } \\
\text { cushingoid } \\
\text { features }\end{array}$ & $\begin{array}{l}\text { Morning headache, } \\
\text { hearing loss, postural } \\
\text { tremor, cushingoid } \\
\text { features }\end{array}$ & $\begin{array}{l}\text { Hearing loss, } \\
\text { Babinski sign }\end{array}$ & $\begin{array}{l}\text { Hearing loss, } \\
\text { Babinski sign }\end{array}$ \\
\hline $\begin{array}{l}\text { Potentially disease- } \\
\text { modifying therapy }\end{array}$ & No & No & No & $\begin{array}{l}\text { Dexameth } \\
(8 \mathrm{mg} / \text { day } \\
\times 7 \text { days and, } \\
\text { then, } 4 \mathrm{mg} / \text { day } \\
\times 7 \text { days })\end{array}$ & $\begin{array}{l}\text { Prednisone } \\
37.5 \mathrm{mg} / \text { day }\end{array}$ & $\begin{array}{l}\text { Prednisone } \\
30 \mathrm{mg} / \text { day, AZA } \\
200 \mathrm{mg} / \text { day }\end{array}$ & $\begin{array}{l}\text { Prednisone } \\
35 \mathrm{mg} / \text { day }\end{array}$ & $\begin{array}{l}\text { Prednisone } \\
30 \mathrm{mg} / \text { day }\end{array}$ & $\begin{array}{l}\text { Prednisone } \\
12.5 / \text { day, } \\
\text { Tocilizumab } \\
800 \mathrm{mg} / 28 \\
\text { days }\end{array}$ & $\begin{array}{l}\text { Methylpred } \\
1,000 \mathrm{mg} / \text { day } \\
\times 5 \text { days }\end{array}$ \\
\hline ESR $(\leq 20 \mathrm{~mm})$ & 104 & 110 & 110 & 35 & 90 & 85 & 100 & 80 & 10 & N/D \\
\hline CRP ( $\leq 5 \mathrm{mg} / \mathrm{L})$ & 61 & 70.7 & 62 & 3 & 45 & 39 & 80 & 53 & 1 & N/D \\
\hline $\begin{array}{l}\text { White Cell }(\% \mathrm{PMN} ; \% \mathrm{~L}) \\
\text { (3,500 to } 10,000 / \mu \mathrm{L} ; \\
40 \text { to } 74 \% ; 19 \text { to } 48 \%)\end{array}$ & $14,100(67.4 ; 22)$ & $12,410(74.7 ; 14.1)$ & $10,060(75.1 ; 15.6)$ & $\begin{array}{l}18,240 \\
(70.6 ; 21.1)\end{array}$ & $\begin{array}{l}18,180(90.5 \\
6.3)\end{array}$ & $\begin{array}{l}12,610(73.6 \\
17.5)\end{array}$ & $\begin{array}{l}12,710 \\
(77.1 ; 13.8)\end{array}$ & $13,680(71.7 ; 19.9)$ & $\begin{array}{l}11,880 \\
(78.5 ; 15.2)\end{array}$ & N/D \\
\hline $\begin{array}{l}\text { Hemoglobin } \\
\text { (14 to } 16 \mathrm{~g} / \mathrm{dl} \text { ) }\end{array}$ & 11.7 & 10.6 & 10.1 & 11.8 & 12.8 & 11.4 & 11.5 & 11.7 & 15.8 & N/D \\
\hline $\begin{array}{l}\text { IL-6 in serum } \\
(\leq 10 \mathrm{pg} / \mathrm{ml})\end{array}$ & $\mathrm{N} / \mathrm{A}$ & N/A & $\mathrm{N} / \mathrm{A}$ & N/A & 44.23 & $22.4^{*}$ & 11.42 & 38.7 & 127 & 44.8 \\
\hline $\begin{array}{l}\text { CSF pressure (5 to } 1 \\
5 \mathrm{CmH}_{2} \mathrm{O} \text { ) }\end{array}$ & N/D & N/D & 40 & 40 & 35 & N/D & N/D & 24 & N/D & Normal \\
\hline $\begin{array}{l}\text { CSF White Cell/ } / \mu l \\
(\mathrm{~L} ; \mathrm{PMN})(\leq 4 / \mu \mathrm{l})\end{array}$ & $16(N / D)$ & $40(25 ; 7)$ & $40(24 ; 12)$ & 2.6 & $24(12 ; 10)$ & $45(20 ; 12)$ & $63(10 ; 47)^{2}$ & $32(26 ; 5)$ & $65(25 ; 22)$ & $8(7.3 ; 0.6)$ \\
\hline $\begin{array}{l}\text { CSF proteins } \\
\text { (10 to } 45 \mathrm{mg} / \mathrm{dl} \text { ) }\end{array}$ & 63 & 84.1 & 98.4 & 33.0 & 73.9 & 90.6 & 98.2 & 123.2 & 102.2 & 54.5 \\
\hline $\begin{array}{l}\text { CSF albumin / serum } \\
\text { albumin × 1,000 }(\leq 6.5)\end{array}$ & 6.37 & 12.36 & 15.51 & 8.37 & 12.08 & 18.26 & 21.18 & 20.59 & 16.86 & 11.12 \\
\hline $\begin{array}{l}\text { Link IgG index }(0.1 \\
\text { to } 0.7) \text {; ReiberlgG } \\
\text { index }(\leq 0)\end{array}$ & $0.66 ;$ N/A & $0.79 ;-5.07$ & $0.96 ; 22.30$ & $0.50 ;-21.95$ & 1.90; 104.57 & $1.01 ; 25,61$ & $1.09 ; 38.59$ & $1.49 ; 118.81$ & $0.77 ;-9.9$ & $0.63 ;-14.89$ \\
\hline OBs (negative) & No (type 1) & No (type 1) & No (type 1) & No (type 1) & No (type 1) & Yes (type 3) & No (type 4) & Yes (type 3) & No (type 4) & No (type 1) \\
\hline $\begin{array}{l}\text { IL-6 in CSF } \\
(\leq 10 \mathrm{pg} / \mathrm{ml})\end{array}$ & $\mathrm{N} / \mathrm{A}$ & $\mathrm{N} / \mathrm{A}$ & $\mathrm{N} / \mathrm{A}$ & 232.8 & 4544 & $\mathrm{~N} / \mathrm{A}$ & 9585 & 5389 & 7874 & 85 \\
\hline ANAs (negative) & N/D & 1:320 & $1: 640$ & $1: 640$ & $1: 40$ & $1: 320$ & $1: 80$ & $1: 80$ & $1: 40$ & $\mathrm{~N} / \mathrm{D}$ \\
\hline $\begin{array}{l}\text { Proteinuria (0 to } \\
150 \mathrm{~g} / \text { day) }\end{array}$ & N/D & N/D & $\mathrm{N} / \mathrm{D}$ & N/D & 800 & 1299 & 460 & 694 & 151 & N/D \\
\hline Other & $\begin{array}{l}\text { Chronic recurrent } \\
\text { osteomyelitis of } \\
\text { the mandible }\end{array}$ & & & - & - & - & $\begin{array}{l}\text { SSA } 62.90 \mathrm{mg} / \mathrm{l} \\
(\mathrm{nv} \leq 6.4)\end{array}$ & $\begin{array}{l}\text { Hepcidin } \\
9.07 \mathrm{nmol} / \mathrm{l} \\
\text { (nv 4.3-7.06) }\end{array}$ & - & - \\
\hline
\end{tabular}
the mandible

${ }^{1}$ Laboratory data obtained from another hospital. ${ }^{2}$ The predominance of polymorphonuclear leukocytes (PMN) in this CSF sample helped us to hypothesize a possible autoinflammatory disease. The values shown in

parentheses in the first column on the left are the normal values. ANAs, antinuclear antibodies; AZA, azathioprine; CRP, C-reactive protein; CSF, cerebrospinal fluid; Dexameth, dexamethasone; Methylpred, methylprednisone; ESR, erythrocyte sedimentation rate; IL-6, interleukin-6; L, lymphocytes; nv, normal value; N/A, Not Available; N/D, Not Done; OBs, oligoclonal bands; PMN, polymorphonuclear leukocytes; SSA, serum A amyloid protein. 
and 3'-UTR, and their flanking intron regions were amplified by the PCR method, purified and directly sequenced. Primers and $\mathrm{PCR}$ conditions are available on request. The c.864C $>\mathrm{G}$ (p.I288M) mutation in NLRP3 and the c.2282G>A (p.R761H) mutation in $M E F V$ were also searched for in the patient's family members (that is, the father, mother, two sisters and one brother) by direct sequencing.

\section{Exome analysis}

To prepare a next-generation sequencing library, genomic DNA was extracted from PBMCs, and randomly fragmented by a Covaris Adaptive Focused Acoustics ${ }^{\mathrm{TM}}$ (AFA) instrument to obtain an average fragment size of 200 to 300 base pairs. Then, the genomic DNA fragments were end-repaired, adenylated, linked to Illuminaspecific adapter sequences, and amplified by PCR. Exome capture was performed using the TruSeq $^{\text {TM }}$ Exome Enrichment Kit (Illumina, San Diego, CA, USA). Sequencing was performed on the Illumina Genome Analyzer HiSeq2000 following the manufacturer's instructions. The average coverage was 20 -fold. The sequencing reads were aligned to the human reference genome hg19 using the Burrows-Wheeler Aligner (BWA) software. We analyzed the data using the Genome Analysis Toolkit (GATK) variant pipeline with respect to 1,000 Genomes Data, Single Nucleotide Polymorphism Database (dbSNP) and in-house data, and we used the SnpEff software to predict the effects of sequence variants.

\section{Body fluid collection}

CSF and/or serum of the patient, patient family members and unrelated controls were used for laboratory analyses on the same day of the sampling or were stored at $-40^{\circ} \mathrm{C}$ in the serum and CSF bank of the Neurological Institute 'Carlo Besta'. Control CSF was obtained from patients with non-inflammatory neurological diseases (that is, brain tumors, neurodegenerative and heredometabolic diseases).

\section{Determination of cytokines and IL-6-R}

IL-1 $\beta$ and soluble IL-6R (sIL-6R) were determined by ELISAs (Human IL-1 $\beta / I L-1 F 2$ Quantikine ELISA Kit, catalogue number DLB50, and Human IL-6 $R$ alpha Quantikine ELISA Kit, catalogue number DR600; R\&D Systems, Minneapolis, MN, USA; www.rndsystems.com). In addition, CSF IL-1 $\beta$ was determined by a high sensitivity immunoassay (Human IL-1ß/IL-1F2 Quantikine HS Immunoassay, catalogue number HSLB00C, R\&D Systems). CSF2/GM-CSF, IFN- $\gamma$, IL-6, IL-8, IL-17A, and TNF$\alpha$ were determined by the Human Inflammatory Cytokines Multi-Analyte ELISArray Kit from SABiosciences (catalogue number MEH-004A; SABiosciences, Frederick, MD, USA; www.sabiosciences.com), and IL-8 and TNF- $\alpha$ concentrations were also determined by ELISA (GE
Healthcare Europe GmbH, Milan, Italy; www.gelifesciences. com). IL- 6 concentrations were determined by an electrochemiluminescent immunoassay (IL6 Elecsys, catalogue number 05109442190, Roche Diagnostics, Mannheim, Germany; www.roche.de) performed using a Cobas E601 analyzer (Roche Diagnostics), whereas the level of $I L$ 6 mRNA was investigated by real-time PCR using standard methods, and $18 S$ as housekeeping gene. In the monocytes of the patient and ten healthy controls, membrane-bound IL-6R was roughly quantified by western blot using an antihuman IL-6 R $\alpha$ antibody (Human IL-6 R alpha Affinity Purified Polyclonal Ab, Goat IgG, AF-227-NA, R\&D Systems) and anti-beta-actin antibody as internal control (Monoclonal Anti- $\beta$-Actin antibody produced in mouseclone AC-15, purified immunoglobulin, buffered aqueous solution, catalogue number A1978, Sigma-Aldrich, Milan, Italy; www.sigmaaldrich.com).

\section{Cell cultures}

Monocytes were obtained from the peripheral blood of the patient, the patient's family members, and healthy controls. In order to determine the IL- $1 \beta$ and IL- 6 secretion in vitro, monocytes were cultured in RPMI Medium 1640 (Invitrogen, Carlsbad, CA, USA; www.invitrogen. com) containing 10\% fetal bovine serum (FBS, Gibco Invitrogen, Carlsbad, CA, USA) for approximately 18 hours at $37^{\circ} \mathrm{C} / 5 \% \mathrm{CO}_{2}$, and then they were activated by 1 $\mu \mathrm{g} / \mathrm{ml}$ of lipopolysaccaride (LPS, catalogue number L6529, Sigma-Aldrich) for 3 hours at $37^{\circ} \mathrm{C}$ in fresh RPMI Medium 1640. For the evaluation of the sole IL-1 $\beta$ secretion, the monocytes were subsequently incubated in the presence of $1 \mathrm{~m} M$ ATP (catalogue number A6419, Sigma-Aldrich) for an additional 15 minutes. Supernatants were collected for quantification of IL- $1 \beta$ and IL-6; for the evaluation of $I L-6$ mRNA levels, RNA was isolated from the monocytes using the QIAamp RNA Blood Mini Kit (catalogue number 52304; Qiagen, Milan, Italy; www.qiagen.com); for the evaluation of membrane-bound IL-6R, proteins were isolated using Laemmli Buffer.

\section{Statistical analyses}

Statistical analyses were performed using GraphPad Prism 5.00 for Windows, GraphPad Software, San Diego California USA, www.graphpad.com.

\section{Ethical approval and patient consent}

Anakinra was administered off-label, the experimental treatment with tocilizumab was approved by the independent ethics committee of the IRCCS Foundation, C. Besta Neurological Institute, and the patient provided written informed consent for both treatments. 


\section{Results}

A novel c.864C $>$ G (p.I288M) NLRP3 missense mutation and the previously described c.2282G $>$ A (p.Arg761His) $M E F V$ mutation were found. No mutation was found in the TNFRSF1A and MVK genes, which are associated with other autoinflammatory diseases, and karyotype and array-CGH analysis (see Additional file 1) were normal [1,6]. The p.I288M mutation - not reported in the INFEVERS registry (http://fmf.igh.cnrs.fr/ISSAID/ infevers/) - is located in exon 3, where most of the pathogenic NLRP3 mutations are located; the isoleucine residue at position 288 is conserved in mammals and birds, and its substitution with methionine is nonconservative. Prediction using the sorting intolerant from tolerant (SIFT) software indicates that the p.I288M substitution is of probable functional importance to the protein. Moreover, only one $M E F V$ mutation was found in a subset of FMF patients, although FMF is traditionally considered an autosomal recessive disease [7], and both NLRP3-related diseases and FMF are IL-1 $\beta$ activation disorders, which may cause aseptic meningitis $[3,4]$. Hence, the combination of these two mutations could actually be pathogenic. However, segregation analysis in the proband's family showed that neither the p.I288M NLRP3 mutation alone nor the combination of the two mutations segregated with the phenotype (Figure 2). Moreover, i) there was no response to the IL-1 receptor antagonist anakinra (Amgen Inc), which is efficacious in IL-1 $\beta$ activation disorders; ii) circulating IL- $1 \beta$ concentration was similar in the serum of the patient $(0.19 \pm$
$0.3 \mathrm{pg} / \mathrm{ml}, \mathrm{n}=12)$ and ten unrelated healthy controls $(0.16 \pm 0.3 \mathrm{pg} / \mathrm{ml})$; iii) no IL- $\beta$ was detected in the CSF of the patient, even with a high sensitivity immunoassay; iv) no difference in IL- $1 \beta$ secretion was observed comparing patient and control monocytes under resting conditions and after LPS alone or LPS followed by ATP stimulation (Figure 3A) [8]. Therefore, atypical IL-1 $\beta$ activation disorders were forcibly excluded.

Therefore, we measured CSF2/GM-CSF, IFN- $\gamma$, IL-6, IL-8, IL-17 $\alpha$, and TNF- $\alpha$ in the patient's serum samples, and we found that, among these cytokines, only IL-6 was increased. Indeed, the IL- 6 concentration evaluated in seven independent samples of the patient's serum, each obtained $\geq 4$ weeks apart, was $37.20 \pm 18.17 \mathrm{pg} / \mathrm{ml}$ (nv $\leq 10 \mathrm{pg} / \mathrm{ml}$ ). On the basis of this finding, and given that the patient has been complaining of neurological symptoms, we also measured IL-6 in patient's CSF samples, and we found that its concentration was much higher than in serum. Indeed, the CSF IL-6 concentration evaluated in five independent samples of the patient's CSF, each obtained $\geq 4$ weeks apart, was 5,432 \pm $2,742 \mathrm{pg} / \mathrm{ml}$ ( $\mathrm{nv} \leq 10 \mathrm{pg} / \mathrm{ml}$ ) (Figure 3B) [9]. For comparison, the CSF IL-6 concentration evaluated in 17 patients with non-inflammatory neurological diseases (that is,thirteen with brain tumors and four with neurodegenerative diseases) was $10.4 \pm 7.8 \mathrm{pg} / \mathrm{ml}$, with a value $\leq 10 \mathrm{pg} / \mathrm{ml}$ in eleven of seventeen patients. Finally, we measured both IL- 8 and TNF- $\alpha$ in at least one patient's CSF sample, and we found that TNF- $\alpha$ was undetectable, whereas IL-8 was increased $(490.3 \mathrm{pg} / \mathrm{ml}, \quad \mathrm{nv}<32)$,

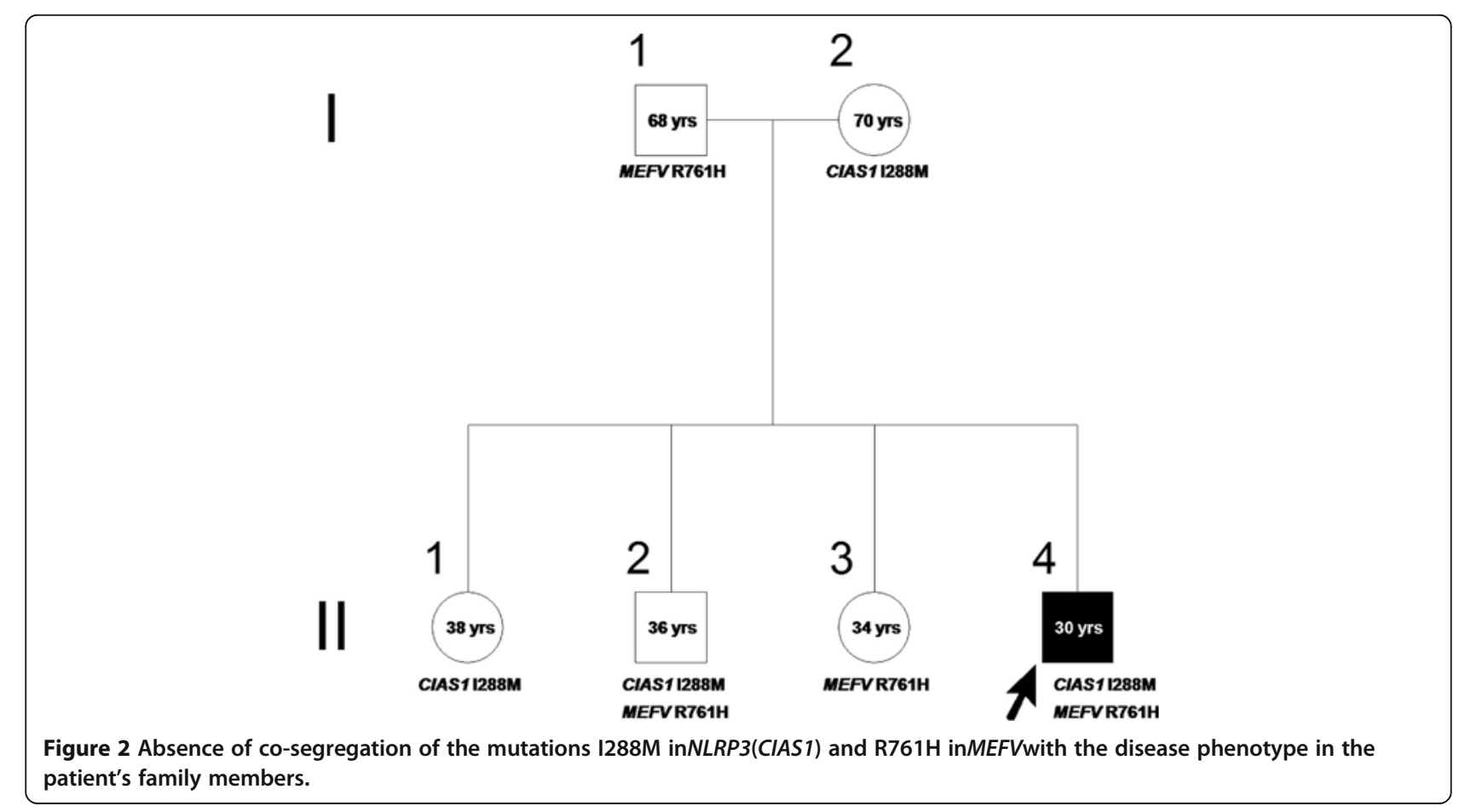




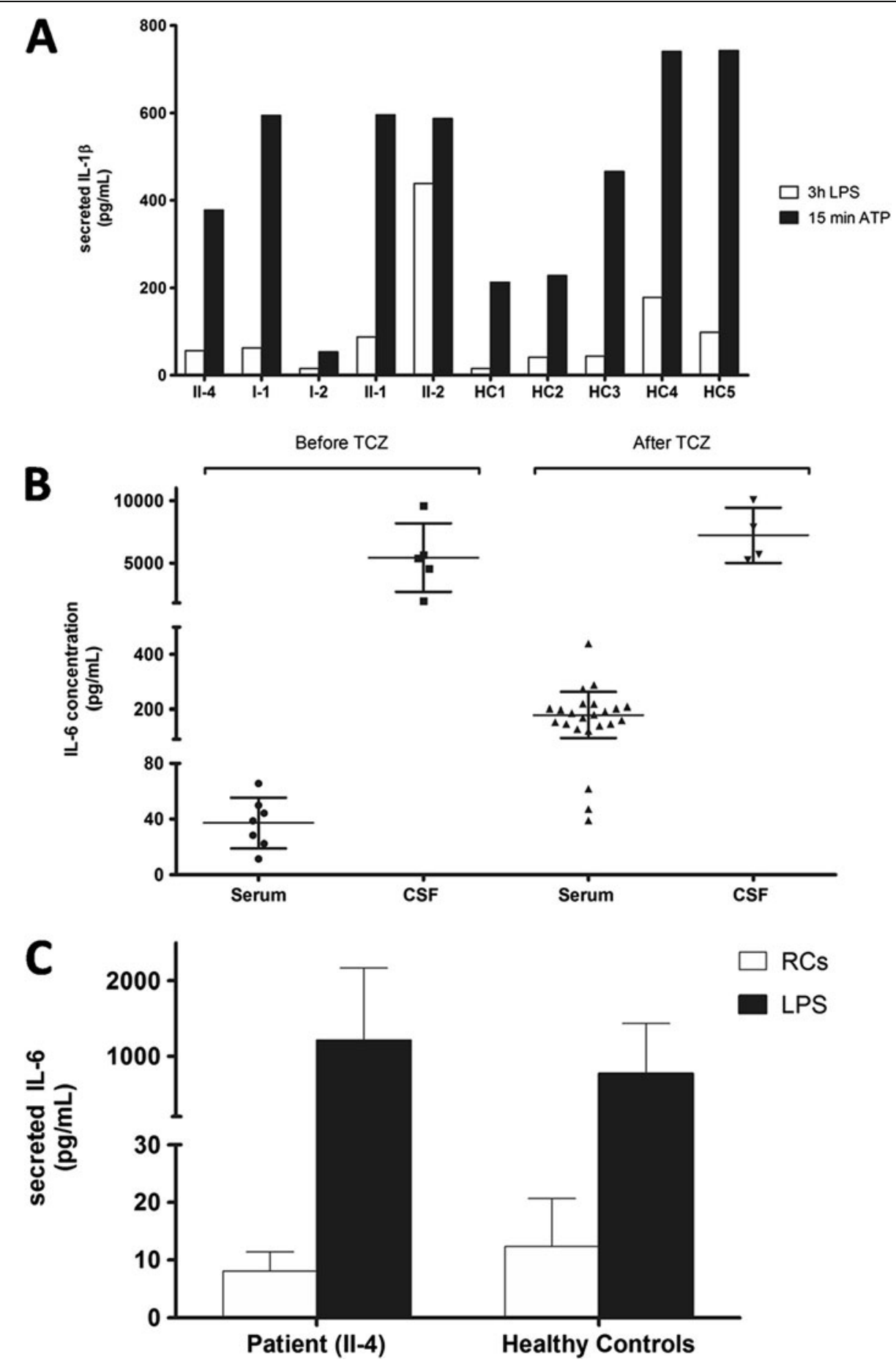

Figure $\mathbf{3}$ (See legend on next page.) 
(See figure on previous page.)

Figure 3 In vitro IL-1 $\beta$ secretion, serum and cerebrospinal fluid (CSF) IL-6 in the patient, and in vitro IL-6 secretion. (A) IL-1 $\beta$ secretion from monocytes of the proband (II-4), his family members (I-1, I-2, II-1 and II-2) and five unrelated healthy controls (HC1-5) after 3 hours of LPS incubation, or 15 minutes of ATP exposure following LPS stimulation, was quantified by ELISA. Results are expressed as pg/ml per $10^{6}$ cells. For the proband the values are the mean of three experiments. Unlike monocytes from patients bearing a pathogenic NLRP3 mutation [8], monocytes from the proband and his family members, harboring the p.I288M NLRP3 (I-2 and II-1), p.R761H MEFV (I-1), or both (II-2 and II-4) mutations, displayed a pattern of IL-1 $\beta$ secretion similar to healthy controls, and characterized by further IL-1 $\beta$ secretion following ATP induction. (B) Serum and CSF IL-6 in our patient before and under tocilizumab (TCZ). Before tocilizumab, IL-6 concentration was evaluated in patient's serum samples $(n=7)$ and CSF samples $(n=5)$, each obtained $\geq 4$ weeks apart. IL-6 was raised in serum (37.20 \pm 18.17 , normal value (nv) $\leq 10 \mathrm{pg} / \mathrm{ml})$ and CSF $(5432 \pm 2742, \mathrm{nv} \leq 10)$ despite a high dose of prednisone. CSF IL-6 concentration was very high, and the mean ratio of CSF IL-6/serum IL-6 was about 146, suggesting that IL-6 is produced in central nervous system (CNS). Under tocilizumab (and prednisone reduction ), serum IL-6 concentration significantly increased (178.8 $\pm 84.14(n=23)$ versus 37.20 $18.17(n=7), P=0.0003$; Mann-Whitney test); the slight increase of CSF IL-6 concentration was not significant ( $7221 \pm 2212$ ( $n=4)$ versus $5432 \pm 2742$ ( $n=5), P=0.2857$; Mann-Whitney test). (C) In vitro IL-6 secretion. IL-6 amounts from monocytes of our patient (Pt) and 13 healthy controls (HCs) are similar under resting conditions (RCs; $8.043 \pm 3.343 \mathrm{pg} / \mathrm{ml}(\mathrm{n}=7)$ versus 12.36 \pm 8.3 ) and after LPS stimulation (LPS; $1209 \pm 956.6 \mathrm{pg} / \mathrm{ml}(\mathrm{n}=7)$ versus $772.7 \pm 663.2)$, further suggesting that the deregulation of IL-6 production occurs primarily in CNS. See Additional file 2 for IL-6 mRNA level analysis.

probably because IL-8 is induced by IL-6 from CSF mononuclear cells [10]. Overall, these data suggest that IL-6 played a key role in the pathogenesis of the disease under investigation.

As a consequence, the patient was treated with the antiIL-6 receptor (IL-6R) monoclonal antibody tocilizumab (Roche), $8 \mathrm{mg} / \mathrm{kg}$ every 28 days. Ten days after the first tocilizumab administration, the blood inflammatory markers normalized (Table 1). Moreover, the steroid intake was rapidly reduced without worsening of symptoms. Progressive disappearance of cushingoid features and postural tremor was observed and the patient definitely stopped complaining about headache after dividing the daily prednisone dose $(12.5 \mathrm{mg} /$ day $)$ between morning (7.5 mg/day) and evening (5 mg/day). However, CSF parameters remained abnormal, and serum IL- 6 concentration, which was evaluated in 23 independent samples of the patient's serum (each obtained about 4 weeks apart), markedly increased to $178.8 \pm 84.14 \mathrm{pg} / \mathrm{ml}$ (nv $\leq 10.0 \mathrm{pg} / \mathrm{ml}$ ) (Figure 3B). This increase is probably due to the inhibition of the clearance of IL- 6 from serum by tocilizumab. In fact, the main elimination pathway of IL- 6 from serum may be from the binding of IL- 6 to IL-6R, including the soluble form. As a consequence, IL-6 may accumulate in serum when the anti-IL-6R monoclonal antibody tocilizumab binds to the IL-6-binding site of its receptor [11]. In contrast, no significant change in the IL-6 concentration was found in four independent samples of the patient's CSF (mean value $7221 \pm 2212 \mathrm{pg} / \mathrm{ml}$ ) (Figure 3B), but we detected a reduction of CSF IL-8 concentration in two independent samples of the patient's CSF (from $490.3 \mathrm{pg} / \mathrm{ml}$ before tocilizumab to $157.0 \mathrm{pg} / \mathrm{ml}$ and, then, $53.0 \mathrm{pg} / \mathrm{ml}(\mathrm{nv}<32.0)$ under tocilizumab). This reduction suggests that tocilizumab may diffuse into CSF, and inhibit the IL-6-mediated effects (though slightly).

The high CSF IL-6/serum IL-6 ratio suggests that IL-6 is produced in the CNS and/or CSF, from which it diffuses into blood (Figure 3B and Table 1). To further corroborate this hypothesis, the IL- 6 secretion between patient and control monocytes under resting conditions and after activation with LPS was compared, and no significant difference was observed (Figure 3C). Moreover, no clear-cut difference was found between the levels of IL-6 mRNA after LPS stimulation (see Additional file 2).

To identify the cause of the chronic IL-6 hypersecretion, we searched for mutations in the IL6 gene, including its $5^{\prime}$ - and 3'-UTRs, and in LIN28A and MIRLET7A3, which encode for molecules involved in the IL- 6 regulatory pathway [12], with no mutation found. We ruled out mutations in the LPIN2, PSMB8 and SH3BP2 genes by using exome analysis, despite these genes having been associated with autoinflammatory diseases with different phenotypes. We investigated the serum concentration of soluble IL-6R (sIL-6R), which mediates the IL-6 clearance, but no clear-cut abnormality was found before or under tocilizumab (see Additional file 3) [11]. Moreover, we found that the amount of membrane-bound IL-6R in the patient's monocytes was similar to that of healthy controls (not shown). Finally, there was no infection by Human Herpes Virus 8 (HHV8), which contains an IL-6 homologous gene [13].

\section{Discussion}

We report a case of chronic inflammatory disease, which can be considered as the prototype of a novel category of autoinflammatory diseases characterized by primary CNS involvement. The key manifestations are chronic meningitis, progressive hearing loss, diffuse white-matter hyperintensity, and persistently raised inflammatory markers. The pathogenic mechanism of this disease is a selective and chronic IL-6 hypersecretion. Indeed, no other cytokine among those investigated was consistently increased in CSF and serum, and the anti-IL-6R monoclonal antibody tocilizumab was partially able to counteract the phenotype. The persistence of abnormal CSF parameters is likely due to the low permeability of the blood brain barrier for tocilizumab. 
Despite extensive laboratory investigations, the cause of IL-6 hypersecretion was not identified. Although patients suffering from autoinflammatory diseases (AID) who are double heterozygotes for mutations in two known AID-associated genes have been reported [14], it is amazing that we found two mutations in known AIDassociated genes (NLRP3 and MEFV) that were proved to be unrelated to the disease under investigation. However, we cannot exclude that the p.I288M NLRP3 variant and the p.R761H $M E F V$ mutation contribute to the inflammatory phenotype in the presence of other genetic or permissive environmental factors triggering IL-6 hypersecretion [2]. Microglia, astroglia, or both, are the likely source of IL- 6 as suggested by IL-6 CSF/serum ratio [5], and by the lack of abnormal IL-6 hypersecretion by patient monocytes in vitro. The condition of our patient, therefore, might be analogous to the neurological disease induced in transgenic mice by IL- 6 cerebral overexpression $[15,16]$.

The CNS hypersecretion of IL-6 may cause: 1) an increased blood-brain barrier permeability, leading to subtle edema. This may explain why there are no focal or diffuse CNS symptoms, and the somatosensory and motor-evoked potentials are near normal (see Additional file 1), despite extensive MRI abnormalities; 2) CSF inflammation with increased intracranial pressure, and 3) inner ear damage [5,17]. Moreover, IL-6 diffusion to the blood compartment may cause the increase of inflammatory markers and chronic anemia (through hepcidin increase), fusion of the feet of podocytes, and proteinuria. Finally, it should be noted that chronic recurrent multifocal osteomyelitis and cherubism are both autoinflammatory diseases [1], suggesting that the chronic recurrent osteomyelitis of the mandible observed in our case may be expression of an autoinflammatory state.

ANA positivity with titer fluctuations (up to 1:640) may suggest a role of autoimmunity in the pathogenesis of the disease, with proportions differing at different phases [18]. However, ANAs may be present in healthy subjects and patients with a variety of diseases, including non-rheumatic diseases [19], and their level may be increased by IL-6 [20]. Therefore, in our case, ANA positivity might be a clinically non-specific finding related to the chronic inflammation.

Chronic monogenic autoinflammatory diseases, including CINCA, autoimmune diseases including neurolupus, and complex diseases with no specific antigen/antibody but with evidence of cellular inflammation, such as neuroBehçet disease and primary angiitis of the CNS, may cause chronic aseptic meningitis, with or without evidence of diffuse white matter abnormalities on brain MRI [5,21-23]. In our case, however, the criteria proposed for the diagnosis of these diseases are not satisfied despite long-term follow up, and the pattern of cytokine production is peculiar. In particular, CNS systemic lupus erythematosus was excluded on the basis of the American College of Rheumathology criteria because of the absence of a wide range of extraneurological manifestations, such as arthritis, dermatitis, and glomerulonephritis, and because of the presence of persistently raised inflammatory markers, leukocytosis and slightly increased (or normal) complement levels (see Additional file 1) [24]. Neuro-Behçet disease was excluded because of the absence of symptoms consistent with focal or multifocal CNS dysfunction, and absence of extraneurological features, namely, oral and genital ulcerations and eye and skin lesions. Moreover, HLA-B*51 was absent, the levels of other pro-inflammatory cytokines were normal [25], and no response to anakinra was obtained [26]. Primary angiitis of the CNS was excluded because of lack of neurological deficit, presence of constantly raised inflammatory markers, and young age at onset [27]. Infectious diseases were also excluded since there was no worsening after the long corticosteroid and immunosuppressive treatment. Castleman disease, a rare disorder biologically characterized by raised serum IL-6 levels, was excluded on the basis of clinical features, unremarkable total-body (18F)-fluorodeoxyglucose-positron emission tomography/ computed tomography, and absence of serum HHV8 DNA and anti-HHV8 antibodies [12].

\section{Conclusions}

This report demonstrates a case of autoinflammatory neurological disease due to IL-6 hypersecretion with aseptic chronic meningitis as the key feature. We suggest that all patients with non-infective chronic meningitis of unknown etiology should be investigated for IL-6 hypersecretion.

\section{Consent}

Written informed consent was obtained from the patient for publication of this case report and any accompanying images. A copy of the written consent is available for review by the Editor-in-Chief of this journal.

\section{Additional files}

\author{
Additional file 1: Neuroradiological, electrophysiological and \\ laboratory data. \\ Additional file 2: Figure showing IL-6 mRNA levels. \\ Additional file 3: Figure showing soluble IL-6 receptor \\ concentrations before and after tocilizumab.
}

\section{Abbreviations}

ADC: Apparent diffusion coefficient; AID: Autoinflammatory disease; ANAs: Antinuclear antibodies; AR: Autosomal recessive; CINCA: Chronic infantile neurologic cutaneous articular syndrome; CNS: Central nervous system; CSF: Cerebrospinal fluid; CT: Computed tomography; ELISA: Enzymelinked immunosorbent assay; FBS: Fetal bovine serum; FMF: Familial Mediterranean fever; HC(s): Healthy control(s); HHV8: Human herpes virus 8; 
IL-6: Interleukin-6; IL-6R: Interleukin-6 receptor; LPS: Lipopolysaccharide; MRI: Magnetic resonance imaging; MWS: Muckle-Wells syndrome; nv: Normal value; PACNS: Primary angiitis of the central nervous system; PBMCs: Peripheral blood mononuclear cells; PCR: Polymerase chain reaction; Pt: Patient; RCs: Resting conditions; sIL-6R: Soluble interleukin-6 receptor; TCZ: Tocilizumab; TNF: Tumor necrosis factor; VEGF: Vascular endothelial growth factor.

\section{Competing interests}

The authors declare that they have no competing interests.

\section{Authors' contributions}

ESa took the lead in drafting the manuscript and has made substantial contributions to study concept and design, acquisition, analysis and interpretation of data, statistical analysis and study coordination. AR, GB and $M L$ carried out determination of cytokines and IL6-R, and performed cell culture experiments. LB, VD, SV and IC carried out sequence analyses and real-time PCR studies. DL, DC, ESt and RP carried out exome analysis and subsequent sequence analyses. LF has been involved in drafting the manuscript, and has made substantial contributions to acquisition, analysis and interpretation of MRI data. MS and DP have been involved in revising the manuscript critically for important intellectual content and have made substantial contributions to analysis and interpretation of clinical and MRI data. FLS has been involved in drafting the manuscript and in revising it critically for important intellectual content, has made substantial contributions to study concept and design, and to analysis and interpretation of laboratory data. All authors read and approved the final manuscript.

\section{Acknowledgments}

We thank the patient and his family and we acknowledge the following colleagues for their insightful comments and suggestions: Massimo Arquati, Ospedale Luigi Sacco, Milano; Antonio Brucato, Ospedali Riuniti di Bergamo, Bergamo; Marco Fasan, Ospedale Luigi Sacco, Milano; Marco Gattorno, Istituto G. Gaslini, Genova; Piergiorgio Messa, Fondazione IRCCS Ca' Granda Ospedale Maggiore Policlinico, Milano, and Giuseppe L Spatoliatore, Ospedale San Giovanni di Dio, Firenze. We also thank Maurizia Baldi, Ospedale Galliera, Genova, for MEFV gene analysis; Domenico Girelli, Policlinico G. B. Rossi, Verona, for the evaluation of the levels of hepcidin; Mariangela Manfredi, Ospedale San Giovanni di Dio, Firenze, for an additional evaluation of the levels of IL-8 and TNF-alpha, and Marina Scarlato, Fondazione San Raffaele del Monte Tabor, Milano, for the evaluation of the levels of VEGF.

\section{Author details}

'UO Neurologia VIII, Department of Clinical Neurosciences, IRCCS Foundation, "C. Besta" Neurological Institute, Milan 20133, Italy. ${ }^{2}$ Laboratory of Clinical Pathology and Medical Genetics, IRCCS Foundation, "C. Besta" Neurological Institute, Milan 20133, Italy. ${ }^{3}$ Cellular Neurobiology Laboratory, Cerebrovascular Disease Unit, IRCCS Foundation, "C. Besta" Neurological Institute, Milan 20133, Italy. ${ }^{4}$ FOM, Fondazione Istituto FIRC di Oncologia Molecolare, Milan 20139, Italy. ${ }^{5}$ Laboratory of Molecular Genetics, Istituto Giannina Gaslini, Genoa 16148, Italy. ${ }^{6}$ Center for Translational Genomics and Bioinformatics, San Raffaele Scientific Institute, Milan 20132, Italy. "Unit of Neuroradiology, IRCCS Foundation, "C. Besta" Neurological Institute, Milan 20133, Italy.

Received: 13 March 2012 Accepted: 2 February 2013 Published: 21 February 2013

\section{References}

1. Masters SL, Simon A, Aksentijevich I, Kastner DL: Horror autoinflammaticus: the molecular pathophysiology of autoinflammatory disease. Annu Rev Immunol 2009, 27:621-668.

2. Aksentijevich I, Kastner DL: Genetics of monogenic autoinflammatory diseases: past successes, future challenges. Nat Rev Rheumatol 2011, 7:469-478.

3. Karachaliou I, Karachalios G, Charalabopoulos A, Charalabopoulos K: Meningitis associated with familial Mediterranean fever. Int J ClinPractSuppl 2005, 147:60-61.
4. Kitley JL, Lachmann HJ, Pinto A, Ginsberg L: Neurologic manifestations of the cryopyrin-associated periodic syndrome. Neurology 2010, 74:1267-1270.

5. Goldbach-Mansky R, Dailey NJ, Canna SW, Gelabert A, Jones J, Rubin BI, Kim HJ, Brewer C, Zalewski C, Wiggs E, Hill S, Turner ML, Karp BI, Aksentijevich I, Pucino F, Penzak SR, Haverkamp MH, Stein L, Adams BS, Moore TL, Fuhlbrigge RC, Shaham B, Jarvis JN, O'Neil K, Vehe RK, Beitz LO, Gardner G, Hannan WP, Warren RW, Horn W, et al: Neonatal-onset multisystem inflammatory disease responsive to interleukin-1 beta inhibition. $N$ Engl J Med 2006, 355:581-592.

6. Reddy S, Jia S, Geoffrey R, Lorier R, Suchi M, Broeckel U, Hessner MJ, Verbsky $\mathrm{J}$ : An autoinflammatory disease due to homozygous deletion of the IL1RN locus. N Engl J Med 2009, 360:2438-2444.

7. Booty MG, Chae JJ, Masters SL, Remmers EF, Barham B, Le JM, Barron KS, Holland SM, Kastner DL, Aksentijevich I: Familial Mediterranean fever with a single MEFV mutation: where is the second hit? Arthritis Rheum 2009, 60:1851-1861.

8. Gattorno M, Tassi S, Carta S, Delfino L, Ferlito F, Pelagatti MA, D'Osualdo A, Buoncompagni A, Alpigiani MG, Alessio M, Martini A, Rubartelli A: Pattern of interleukin-1 beta secretion in response to lipopolysaccharide and ATP before and after interleukin-1 blockade in patients with CIAS1 mutations. Arthritis Rheum 2007, 56:3138-3148.

9. Kestner $M$, Rosler $A E$, Baumgärtner $M$, Lindner $A$, Orth $M$ : CSF interleukin 6 - a useful biomarker of meningitis in adults?/Liquor Interleukin 6 einsinnvoller Biomarker für die Meningitis beimErwachsenen. Laboratoriums Medizin 2011, 35:107-113.

10. Hashizume M, Higuchi Y, Uchiyama Y, Mihara M: IL-6 plays an essential role in neutrophilia under inflammation. Cytokine 2011, 54:92-99.

11. Nishimoto N, Terao K, Mima T, Nakahara H, Takagi N, Kakehi T: Mechanisms and pathologic significances in increase in serum interleukin-6 (IL-6) and soluble IL-6 receptor after administration of an anti-IL- 6 receptor antibody, tocilizumab, in patients with rheumatoid arthritis and Castleman disease. Blood 2008, 112:3959-3964.

12. Iliopoulos D, Hirsch HA, Struhl K: An epigenetic switch involving NFkappaB, Lin28, Let-7 MicroRNA, and IL6 links inflammation to cell transformation. Cell 2009, 139:693-706.

13. El-Osta HE, Kurzrock R: Castleman's disease: from basic mechanisms to molecular therapeutics. Oncologist 2011, 16:497-511.

14. Singh-Grewal D, Chaitow J, Aksentijevich I, Christodoulou J: Coexistent MEFV and CIAS1 mutations manifesting as familial Mediterranean fever plus deafness. Ann Rheum Dis 2007, 66:1541.

15. Campbell IL, Abraham CR, Masliah E, Kemper P, Inglis JD, Oldstone MB, Mucke L: Neurologic disease induced in transgenic mice by cerebral overexpression of interleukin 6. Proc Natl Acad Sci USA 1993, 90:10061-10065.

16. Brett FM, Mizisin AP, Powell HC, Campbell IL: Evolution of neuropathologic abnormalities associated with blood-brain barrier breakdown in transgenic mice expressing interleukin-6 in astrocytes. J Neuropathol Exp Neurol 1995, 54:766-775.

17. Wakabayashi K, Fujioka M, Kanzaki S, Okano HJ, Shibata S, Yamashita D, Masuda M, Mihara M, Ohsugi Y, Ogawa K, Okano H: Blockade of interleukin-6 signaling suppressed cochlear inflammatory response and improved hearing impairment in noise-damaged mice cochlea. Neurosci Res 2010, 66:345-352.

18. Nishimura $H$, Strominger JL: Involvement of a tissue-specific autoantibody in skin disorders of murine systemic lupus erythematosus and autoinflammatory diseases. ProcNat/AcadSci USA 2006, 103:3292-3297.

19. Solomon DH, Kavanaugh AJ, Schur PH: American College of Rheumatology Ad Hoc Committee on Immunologic Testing Guidelines: Evidence-based guidelines for the use of immunologic tests: antinuclear antibody testing. Arthritis Rheum 2002, 47:44-434.

20. Illei GG, Shirota Y, Yarboro CH, Daruwalla J, Tackey E, Takada K, Fleisher T, Balow JE, Lipsky PE: Tocilizumab in systemic lupus erythematosus: data on safety, preliminary efficacy, and impact on circulating plasma cells from an open-label phase I dosage-escalation study. Arthritis Rheum 2010, 62:542-552.

21. Cohen BA: Chronic meningitis. Curr Neurol Neurosci Rep 2005, 5:429-439.

22. Prabhakaran S, Bramlage M, Edgar MA, Diamond B, Hardin JA, Volpe BT: Overwhelming leukoencephalopathy as the only sign of neuropsychiatric lupus. J Rheumatol 2005, 32:1843-1845.

23. Ginsberg L, Kidd D: Chronic and recurrent meningitis. Pract Neurol 2008, 8:348-361

24. Joseph FG, Scolding NJ: Neurolupus. Pract Neurol 2010, 10:4-15 
25. Hamzaoui K, Hamzaoui A, Guemira F, Bessioud M, Hamza M, Ayed K: Cytokine profile in Behçet's disease patients. Relationship with disease activity. Scand J Rheumatol 2002, 31:205-210.

26. Botsios C, Sfriso P, Furlan A, Punzi L, Dinarello CA: Resistant Behçet disease responsive to anakinra. Ann Intern Med 2008, 149:284-286.

27. Birnbaum J, Hellmann DB: Primary angiitis of the central nervous system. Arch Neurol 2009, 66:704-709.

doi:10.1186/1742-2094-10-29

Cite this article as: Salsano et al: An autoinflammatory neurological

disease due to interleukin 6 hypersecretion. Journal of Neuroinflammation $201310: 29$

\section{Submit your next manuscript to BioMed Central and take full advantage of:}

- Convenient online submission

- Thorough peer review

- No space constraints or color figure charges

- Immediate publication on acceptance

- Inclusion in PubMed, CAS, Scopus and Google Scholar

- Research which is freely available for redistribution 